\title{
SIFAT DEFINIT NON-NEGATIF FUNGSI KARAKTERISTIK DARI SEBARAN BINOMIAL NEGATIF MAJEMUK SEBAGAI PENJUMLAHAN SEBARAN EKSPONENSIAL
}

\author{
STEFI AMALIA PUTRI \\ Program Studi Magister Matematika, \\ Fakultas Matematika dan Ilmu Pengetahuan Alam, Universitas Andalas, \\ Kampus UNAND Limau Manis Padang, Indonesia, \\ email : stefiamaliafitri27@gmail.com
}

\begin{abstract}
Abstrak. Sebaran binomial negatif majemuk sebagai penjumlahan sebaran eksponensial adalah penjumlahan sebaran eksponensial yang saling bebas, dimana banyaknya sebaran tersebut menyebar menurut sebaran binomial negatif. Paper ini memperlihatkan sifat definit non-negatif fungsi karakteristik dari suatu sebaran binomial negatif majemuk sebagai penjumlahan sebaran eksponensial yang ditunjukan dengan memperlihatkan sifat kekontinuan dan bentuk kuadratik.
\end{abstract}

Kata Kunci: Sebaran binomial negatif majemuk, Sebaran eksponensial, Fungsi karakteristik, Fungsi definit non-negatif

$\begin{array}{lll}\text { Diterima } & : & \text { 26 Juli } 2018 \\ \text { Direvisi } & : & \text { 17 September } 2018 \\ \text { Dipublikasikan } & : & \text { 21 Desember 2018 }\end{array}$

\section{Pendahuluan}

Percobaan binomial negatif dapat juga disebut sebagai percobaan Bernoulli yang dilakukan sampai terjadi $r$ buah sukses, dengan setiap pengulangannya saling bebas dimana peluang gagalnya yaitu $1-p$ dan peluang sukses $p$. Misalkan peubah acak $N$ menyatakan jumlah percobaan yang dibutuhkan sampai terjadi $r$ sukses, maka sebaran peluang dari $N$ disebut sebaran binomial negatif dengan fungsi kepekatan

$$
f_{N}(n)=P(N=n)=\left(\begin{array}{c}
r+n-1 \\
n
\end{array}\right) p^{r}(1-p)^{n}
$$

dimana $n=0,1,2, \cdots$ dan $0 \leq p \leq 1$.

Adapun fungsi karakteristik dari peubah acak $N$ yang berdistribusi binomial negatif dapat dirumuskan sebagai berikut

$$
\begin{aligned}
\varphi_{N}(t) & =E_{N}\left(e^{i t N}\right) \\
& =\sum_{n=0}^{\infty} e^{i t n}\left(\begin{array}{c}
r+n-1 \\
n
\end{array}\right) p^{r}(1-p)^{n} \\
& =p^{r} \sum_{n=0}^{\infty}\left(\begin{array}{c}
r+n-1 \\
n
\end{array}\right)\left((1-p) e^{i t}\right)^{n}
\end{aligned}
$$


misalkan $1-p^{*}=(1-p) e^{i t}$, maka

$$
\begin{aligned}
& =p^{r} \sum_{n=0}^{\infty}\left(\begin{array}{c}
r+n-1 \\
n
\end{array}\right)\left(1-p^{*}\right)^{n} \frac{\left(p^{*}\right)^{r}}{\left(p^{*}\right)^{r}} \\
& =\frac{p^{r}}{\left(p^{*}\right)^{r}} \sum_{n=0}^{\infty}\left(\begin{array}{c}
r+n-1 \\
n
\end{array}\right)\left(1-p^{*}\right)^{n}\left(p^{*}\right)^{r} \\
& =\left(\frac{p}{\left(1-(1-p) e^{i t}\right)}\right)^{r}
\end{aligned}
$$

Misalkan $X$ variabel acak dari sebaran eksponensial dengan parameter $\lambda$. Fungsi kepekatan peluang dari variabel acak ini diberikan

$$
f_{X}(x)=\lambda e^{-\lambda x}
$$

untuk $\lambda$ positif dan semua $x$ bilangan riil positif. Fungsi karakteristik dari peubah acak $X$ adalah

$$
\begin{aligned}
\varphi_{X}(t) & =E\left(e^{i t X}\right) \\
& =\int_{0}^{\infty} e^{i t X} \lambda e^{-\lambda x} d x \\
& =\lambda \int_{0}^{\infty} e^{i t x-\lambda x} d x \\
& =\frac{\lambda}{(\lambda-i t)}
\end{aligned}
$$

Pada bagian ini telah dijelaskan tentang fungsi karakteristik dari sebaran binomial negatif dan eksponensial. Selanjutnya pada Bagian 2 akan dijelaskan tentang fungsi karakteristik dari sebaran binomial negatif majemuk sebagai penjumlahan sebaran eksponensial. Sedangkan Bagian 3 akan menjelaskan tentang sifat definit non-negatif fungsi karakteristik dari sebaran binomial negatif majemuk sebagai penjumlahan sebaran eksponensial.

\section{Fungsi Karakteristik dari Sebaran Binomial Negatif Majemuk sebagai Penjumlahan Sebaran Eksponensial}

Pada bagian ini akan dibahas tentang fungsi karakteristik sebaran binomial negatif majemuk sebagai penjumlahan sebaran eksponensial dengan konstanta penstabil. Misalkan $S=X_{1}+X_{2}+\cdots+X_{N}$, peubah acak $X_{i}$ identik dan saling bebas serta menyebar eksponensial dengan parameter $\lambda$ dan saling bebas terhadap peubah acak $N$ menyebar binomial negatif $(p, r)$, maka peubah acak $S$ disebut sebaran binomial negatif majemuk sebagai penjumlahan sebaran eksponensial dengan konstanta penstabil.

Teorema 2.1. Misalkan $S=X_{1}+X_{2}+\cdots+X_{N}$ dimana $X_{i}$ dan $N$ masingmasing merupakan peubah acak dan $X_{i}$ peubah acak yang saling bebas dan identik (iid), maka fungsi karakteristik dari peubah acak $S$ adalah

$$
\varphi_{S}(t)=M_{N}\left(\ln \left(\varphi_{X}(t)\right)\right) .
$$


Bukti. Berdasarkan definisi fungsi karakteristik diperoleh,

$$
\begin{aligned}
\varphi_{S}(t) & =E_{S}\left(e^{i t S}\right), \\
& \left.=E_{N}\left(E_{X_{i}}\left(e^{i t\left(X_{1}+X_{2}+\cdots+X_{N}\right)}\right) \mid N\right)\right), \\
& \left.=E_{N}\left(E_{X_{1}}\left(e^{i t X_{1}}\right) E_{X_{2}}\left(e^{i t X_{2}}\right) \cdots E_{X_{N}}\left(e^{i t X_{N}}\right)\right)\right), \\
& =E_{N}\left(\varphi_{X}(t)^{N}\right), \\
& =M_{N}\left(\ln \left(\varphi_{X}(t)\right)\right) .
\end{aligned}
$$

Proposisi 2.2. Misalkan $S$ adalah suatu peubah acak yang menyebar menurut sebaran binomial negatif majemuk sebagai penjumlahan sebaran eksponensial, maka fungsi karakteristik dari peubah acak $S$ adalah

$$
\varphi_{S}(t)=\left[\frac{p}{\left(1-(1-p) \frac{\lambda}{\lambda-i t}\right)}\right]^{r} .
$$

Bukti. Fungsi karakteristik dari sebaran binomial negatif majemuk sebagai penjumlahan sebaran eksponensial dapat dirumuskan sebagai berikut

$$
\begin{aligned}
\varphi_{S}(t) & =M_{N}\left[\ln \left(\varphi_{X}(t)\right)\right], \\
& =\left[\frac{p}{\left(1-(1-p) \varphi_{X}(t)\right)}\right]^{r}, \\
& =\left[\frac{p}{\left(1-(1-p) \frac{\lambda}{\lambda-i t}\right)}\right]^{r} .
\end{aligned}
$$

Jadi, fungsi karakteristik dari sebaran Binomial Negatif-Eksponensial adalah $\varphi_{S}(t)=\left[\frac{p}{\left(1-(1-p) \frac{\lambda}{\lambda-i t}\right)}\right]^{r}$.

\section{Sifat Definit Non-Negatif Fungsi Karakteristik dari Sebaran Binomial Negatif Majemuk sebagai Penjumlahan Sebaran Eksponensial}

Akan diperkenalkan fungsi definit non-negatif yang merupakan syarat perlu dan cukup untuk fungsi karakteristik. Sebuah fungsi bernilai kompleks $\varphi_{X}(t)$ dengan $t$ bilangan riil dikatakan fungsi definit non-negatif jika dua kondisi berikut dipenuhi[4]:

(1) $\varphi_{X}(t)$ adalah kontinu

(2) bentuk kuadrat $\sum_{1 \leq j \leq n} \sum_{1 \leq l \leq n} c_{j} \overline{c_{l}} \varphi_{X}\left(t_{j}-t_{l}\right) \geq 0$, untuk sebarang bilangan komplek $c_{1}, c_{2}, \cdots, c_{n}$ dan bilangan riil $t_{1}, t_{2}, \cdots, t_{n}$ dan $n \geq 1$.

Proposisi 3.1. Misalkan $S$ adalah suatu peubah acak yang menyebar menurut sebaran binomial negatif majemuk sebagai penjumlahan sebaran eksponensial, dengan fungsi karakteristik sebagai berikut

$$
\varphi_{S}(t)=\left[\frac{p}{\left(1-(1-p) \frac{\lambda}{\lambda-i t}\right)}\right]^{r}
$$


maka fungsi $\varphi_{S}(t)$ adalah fungsi definit non-negatif.

Bukti. Fungsi $\varphi_{S}(t)$ adalah fungsi definit non-negatif, Jika

(1) Fungsi karakteristik $\varphi_{S}(t)$ kontinu. Kekontinuan $\varphi_{S}(t)$ akan dibuktikan melalui kekontinuan seragam.

Misalkan $\varphi_{S}(t)$ adalah suatu fungsi karakteristik dan $h=s-t, s>t$. Akan ditunjukan bahwa setiap $\epsilon>0$ terdapat $\delta>0$ sedemikian sehingga $\mid \varphi_{S}(s)-$ $\varphi_{S}(t) \mid<\epsilon$, jika $|s-t|<\delta$. Perhatikan bahwa

$$
\begin{aligned}
\left|\varphi_{S}(s)-\varphi_{S}(t)\right| & =\left|\left(\frac{p}{\left(1-(1-p) \frac{\lambda}{\lambda-i s}\right)}\right)^{r}-\left(\frac{p}{\left(1-(1-p) \frac{\lambda}{\lambda-i t}\right)}\right)^{r}\right| \\
& =p^{r}\left|\left(\frac{1}{\left(1-\frac{(1-p) \lambda}{\lambda-i s}\right)}\right)^{r}-\left(\frac{1}{\left(1-\frac{(1-p) \lambda}{\lambda-i t}\right)}\right)^{r}\right| \\
& =p^{r}\left|\left(\sum_{k=0}^{\infty}\left(\frac{(1-p) \lambda}{\lambda-i s}\right)^{k}\right)^{r}-\left(\sum_{k=0}^{\infty}\left(\frac{(1-p) \lambda}{\lambda-i t}\right)^{k}\right)^{r}\right|
\end{aligned}
$$

Misal $h=s-t$ dan $h \rightarrow 0$ maka,

$$
\begin{aligned}
& \left|\varphi_{S}(h+t)-\varphi_{S}(t)\right|=p^{r}\left|\left(\sum_{k=0}^{\infty}\left(\frac{(1-p) \lambda}{\lambda-i(h+t)}\right)^{k}\right)^{r}-\left(\sum_{k=0}^{\infty}\left(\frac{(1-p) \lambda}{\lambda-i t}\right)^{k}\right)^{r}\right| \\
& \rightarrow 0
\end{aligned}
$$

Ini menunjukan untuk $\delta<\epsilon$ dimana $\left|\varphi_{S}(h+t)-\varphi_{S}(t)\right|$ untuk $|s-t|<\delta$ dan $\delta$ bergantung pada $\epsilon$, maka $\varphi_{S}(t)$ adalah kontinu seragam.

(2) Bentuk kuadrat $\sum_{1<j, l<n} c_{j} \overline{c_{l}} \varphi_{S}\left(t_{j}-t_{l}\right) \geq 0$, untuk sebarang bilangan komplek $c_{1}, c_{2}, \cdots, c_{n}$ dan bilangan riil $t_{1}, t_{2}, \cdots, t_{n}$ dan $n \geq 1$.

Perhatikan bahwa

$$
\begin{aligned}
\sum_{1 \leq j, l \leq n} c_{j} \overline{c_{l}} \varphi_{S}\left(t_{j}-t_{l}\right) & =\sum_{1 \leq j, l \leq n} c_{j} \overline{c_{l}}\left(\frac{p}{\left(1-(1-p) \frac{\lambda}{\lambda-i\left(t_{j}-t_{l}\right)}\right)}\right)^{r} \\
& =p^{r} \sum_{1 \leq j, l \leq n} c_{j} \overline{c_{l}}\left(\frac{1}{\left(1-\frac{(1-p) \lambda}{\lambda-i\left(t_{j}-t_{l}\right)}\right)}\right)^{r} \\
& =p^{r} \sum_{1 \leq j, l \leq n} c_{j} \overline{c_{l}}\left(\sum_{k=0}^{\infty}\left(\frac{(1-p) \lambda}{\lambda-i\left(t_{j}-t_{l}\right)}\right)^{k}\right)^{r} \\
& =p^{r} \sum_{1 \leq j, l \leq n}\left(\sum _ { k = 0 } ^ { \infty } ( 1 - p ) ^ { k } \lambda ^ { k } \left(c_{j}^{\frac{1}{r}}\left(\frac{1}{\lambda-i t_{j}}\right)^{k} \frac{\left.\left.c_{l}^{\frac{1}{r}}\left(\frac{1}{\lambda+i t_{l}}\right)^{k}\right)\right)^{r}}{r}\right.\right. \\
& =p^{r} \sum_{1 \leq j \leq n}\left(\sum_{k=0}^{\infty}(1-p)^{k} \lambda^{k}\left|c_{j}^{\frac{1}{r}}\left(\frac{1}{\lambda-i t_{j}}\right)^{k}\right|^{r}\right. \\
& \geq 0 .
\end{aligned}
$$

Karna dua kondisi diatas terpenuhi, maka dapat dikatakan fungsi $\varphi_{S}(t)$ adalah fungsi definit non-negatif. 


\section{Daftar Pustaka}

[1] Bain, L.J. dan M. Engelhardt. 1992. Introduction to Probability and Mathematical Statistics Second Edition. Duxbury Press, California.

[2] Chung, K. L. 2001. A Course In Probability Theory. $3^{\text {rd }}$ ed. San Diego: Academy Press

[3] Devianto, D. Maiyastri, Oktasari, L. and Anas, M.. 2015. Convolution of generated random variable from exponential distribution with stabilizer constant. Applied Mathematical Sciences, 4781 - 4789

[4] Devianto, D. Maiyastri, Handayani, D. 2017. The Infinitely Divisible Characteristic Function and its Canonical Representation Property of Compound Negative Binomial Distribution. Akan terbit pada jurnal Probability and Statistical Mathematics

[5] Furman, E. 2007. On the Convolution of the Negative Binomial Random Variables. Statistics and Probability Letter. $77169-172$

[6] Lukacs, E. 1992. Characteristic Function. $2^{\text {nd }}$ ed. London: Griffin

[7] Panjer, H. H. dan G. E. Willot. 1981. Finite Sum Evaluation of The Negative Binomial-Eksponensial Model. Astin Bulletin. 133 - 137

[8] Wang, Z. 2011. One Mix Negative Binomial Distribution with Application. Statistical Planning, 141, 1153 - 1160 